\title{
It is time to focus on pre-hospital delays in patients with ST-segment elevation myocardial infarction
}

\author{
Hack-Lyoung Kim
}

Division of Cardiology, Department of Internal Medicine, Seoul Metropolitan Government Seoul National University Boramae Medical Center, Seoul, Korea

Received: November 25, 2019 Accepted: November 30, 2019

\section{Correspondence to}

Hack-Lyoung Kim, M.D. Division of Cardiology, Department of Internal Medicine, Seoul Metropolitan Government Seoul National University Boramae Medical Center, 20 Boramae-ro 5-gil, Dongjak-gu, Seoul o7o61, Korea

Tel: +82-2-831-0714

Fax: $+82-2-870-3235$

E-mail: khl2876@gmail.com https://orcid.org/0000-00026703-1472

\section{See Article on Page 119-132}

Rapid myocardial reperfusion is the cornerstone of treatment for patients with ST-elevation myocardial infarction (STEMI). A longer total ischemic time (TIT), measured from symptom onset to reperfusion, results in more severe myocardial damage and a poorer clinical prognosis. Indeed, it has been suggested that every 30 minutes of treatment delay increases the death risk by $7.5 \%$ [1]. Therefore, minimizing TIT is essential. Although many efforts have been made to reduce in-hospital delays (door-to-balloon time [DTBT]), pre-hospital delays (symptom-to-door-time [STDT]) have not been reduced. A recent study using the Korean Percutaneous Coronary Intervention (K-PCI) registry showed that the median DTBT was 62 minutes and the median STDT 94 minutes [2]; the STDT now principally determines the TIT. Therefore, the identification and control of factors associated with a longer STDT is important.

In this issue of the Korean Journal of Internal Medicine, Lee et al. [3] investigated 4,874 STEMI patients whose data were stored in a nationwide registry of acute myocardial infarction, and found that older age, female sex, repeat ischemia, and non-utilization of emergency medical services (EMSs) were associated with a longer STDT; these findings are in line with those of previous studies $[4,5]$. Symptom awareness is critical; patients then seek help, affecting decision-making in terms of additional early reperfusion therapy [6]. In recent decades, sex and gender differences in terms of ischemic heart disease have received increased attention. In females, the detection and evaluation of ischemic heart disease is more difficult than in males; this has often been attributed to atypical symptoms, less reliable electrocardiographic findings and cardiac markers, and socioeconomic barriers [7-9]. Although the findings remain controversial, many studies have shown that females visit hospitals more often after symptoms occur $[9,10]$. It is necessary to educate elderly females on the identification of ischemic symptoms and the importance of immediate access to healthcare when a suspicious symptom develops. Effort should also be made to increase EMS utilization; the STDT is reduced by rapid transportation to a percutaneous coronary intervention (PCI)-capable center and by expediting emergency department processes. Therefore, community education should focus not only on the importance of recognizing the symp- 
toms of myocardial infarction, but also on taking early action (calling an EMS). A recent study found that smartphone use effectively reduced the TIT of STEMI patients, especially that associated with the transfer from a non-PCI-capable to a PCI-capable hospital; patients using smartphone social network systems had a shorter, median, first, medical contact-to-device time than others (102.5 minutes vs. 129.5 minutes, $p=0.031$ ) [11]. Korea is an information technology powerhouse; pre-hospital triage via telemedicine may effectively reduce the time to life-saving reperfusion therapy in STEMI patients.

In summary, it is essential to reduce the TIT not just within hospitals but by educating the public about the importance of recognizing myocardial infarction symptoms and prompt activation of an EMS. Elderly females require special education.

\section{Conflict of interest}

No potential conflict of interest relevant to this article was reported.

\section{REFERENCES}

1. De Luca G, Suryapranata H, Ottervanger JP, Antman EM. Time delay to treatment and mortality in primary angioplasty for acute myocardial infarction: every minute of delay counts. Circulation 2004;109:1223-1225.

2. Shin DH, Kang HJ, Jang JS, et al. The current status of percutaneous coronary intervention in Korea: based on year 2014 \& 2016 cohort of Korean Percutaneous Coronary Intervention (K-PCI) registry. Korean Circ J 2019;49:1136-1151.

3. Lee $\mathrm{SH}$, Kim HK, Jeong MH, et al. Pre-hospital delay and emergency medical services in acute myocardial infarc- tion. Korean J Intern Med 2019;35:119-132.

4. Goldberg RJ, Steg PG, Sadiq I, et al. Extent of, and factors associated with, delay to hospital presentation in patients with acute coronary disease (the GRACE registry). Am J Cardiol 2002;89:791-796.

5. Nielsen CG, Laut KG, Jensen LO, Ravkilde J, Terkelsen CJ, Kristensen SD. Patient delay in patients with ST-elevation myocardial infarction: time patterns and predictors for a prolonged delay. Eur Heart J Acute Cardiovasc Care 2017;6:583-591.

6. Peng YG, Feng JJ, Guo LF, et al. Factors associated with prehospital delay in patients with ST-segment elevation acute myocardial infarction in China. Am J Emerg Med 2014;32:349-355.

7. Shah AS, Griffiths M, Lee KK, et al. High sensitivity cardiac troponin and the under-diagnosis of myocardial infarction in women: prospective cohort study. BMJ 2015;350:97873.

8. Cho DH, Choi J, Kim MN, et al. Gender differences in the presentation of chest pain in obstructive coronary artery disease: results from the Korean Women's Chest Pain Registry. Korean J Intern Med 2019 Mar 19 [Epub]. https:// doi.org/10.3904/kjim.2018.320.

9. Nguyen HL, Gore JM, Saczynski JS, et al. Age and sex differences and 20-year trends (1986 to 2005) in prehospital delay in patients hospitalized with acute myocardial infarction. Circ Cardiovasc Qual Outcomes 2010;3:590-598.

10. Kaul P, Armstrong PW, Sookram S, Leung BK, Brass N, Welsh RC. Temporal trends in patient and treatment delay among men and women presenting with ST-elevation myocardial infarction. Am Heart J 2011;161:91-97.

11. Park JJ, Yoon CH, Suh JW, et al. Reduction of ischemic time for transferred STEMI patients using a smartphone social network system. J Am Coll Cardiol 2016;68:149o1492. 